\title{
Role of Weed Emergence Time for the Relative Seed Production in Maize
}

\author{
Stefano Benvenuti* \\ Dipartimento di Agronomia e Gestione dell'Agroecosistema, Università di Pisa \\ Via S. Michele degli Scalzi 2, 56124 Pisa, Italy
}

Received: 22 February 2006. Accepted: 7 July 2006

\begin{abstract}
Trials were carried out in 2000 and 2001 to investigate the effect of weed emergence time on weed seed production in a maize field. Datura stramonium L., Solanum nigrum L. and Abutilon theophrasti Medicus were selected for their importance as summer weeds. Emergence time was found to be crucial since delay would involve an unfavourable light environment determined by crop canopy elongation and resulting shade production. Only the early emergence of $D$. stramonium and $A$. theophrasti showed the capacity to exposing their leaves over the crop canopy. Generally the weed seed production under shade conditions decreased for the reduction of the fruit per plant since the number of seed per plant showed only a light reduction. However, while D. stramonium and A. theophrasti compete with the crop by increasing height, Solanum nigrum tends to adjust to shade without excessive reduction in number of seeds produced. Thus in D. stramonium and A. theophrasti late emergence reduced seed production to only $15 \%$, while S. nigrum maintained $25 \%$ of the seed production level generally observed with greater light exposure. This environmental adaptation was confirmed by the less marked decrease in S. nigrum harvest index. Agroecological involvements are discussed.
\end{abstract}

Key-words: weed seed production, shade, weed-crop competition, seed dispersal, seedbank dynamics.

\section{Introduction}

It is widely believed that rational weed management in the agroecosystems requires knowledge of the biology of the various species in terms of reproduction and growth (Mortensen et al., 2000), in order to predict and optimize the relationships between agronomic practices and weed dynamics. Studies on the assessment of seedbank dynamics following diversified agronomic inputs (Buhler, 1999) are clear examples of the importance attributed to knowledge of the survival strategies adopted by the various species. For it is precisely by evolving specific strategies (Baker, 1974) that weed species have succeeded in persisting in typically disturbed agronomic environments.

The survival strategies in question involve the evolution of such characteristics as seed dormancy (Mapes et al., 1989), longevity (Burnside et al., 1996), and sensitivity to crucial environmental factors (light, humidity, temperature, etc.). These enable weeds to synchronize germi- nation with more favourable periods, thereby providing weed seeds with greater chances of completing the biological cycle (Benvenuti and Macchia, 1997). However, another fundamental strategy observed in weed species is the rapid and elevated seed production even if the crop canopy light environment represent an obstacle to reproduction activity (Brainard et al., 2005). Together with the above mentioned dormancy and long life characteristics, this characteristic enables weed seeds to form a persistent seedbank (Thompson and Grime, 1979), and hence to continue infesting the agroecosystem over a prolonged period. This fast and elevated seed production capacity, has led to the definition of ruderal weeds (Grime, 1979), which devote most of their energy resources to rapid production of large amounts of seeds (Moss, 1983; Perron and Légère, 2000). Some Authors (Sattin et al., 1992) point out that agronomic measures designed to minimize annual seed production in such ruderal species constitutes a fundamental management practice for prevention of infestation. 
The pattern of prolonged germination and emergence, typically shown by many weeds, is linked to a diversified seed production capacity as a function of the relative emergence time. One interesting finding is that most of the annual inputs to the seedbank result from lateemerging plants which escape the action of both mechanical (hoeing) and chemical (herbicides) agronomic disturbance. Of increasing interest is also the assessment of the seed production capacity of those weed species for which it is not economical to use herbicides, in that such weeds remain below the intervention threshold (Cardina and Norquay, 1997). In these cases weeds tend to develop freely and hence succeed in completing their biological cycle and dispersing their seeds in spite of the predatction activity of the present micro-fauna (Mauchline et al., 2005). In this background the prediction of the weed seed production, as a function of the crop interference, play a crucial role in the evaluation of the knowledge of a new criterion of "threshold limits" for weed convenience based not only on the actual crop injury but even in the future damage due to the annual seedbank input. In spite of the difficulties on the quantifying the weed seed production recently were carried out studies based on the empirical and theoretical relationship between wed seed production and crop yield loss data (Canner et al., 2002).

The aim of this study was to investigate the effective seed production in some important weeds infesting a typical summer crop, assessing seed production as a function of emergence time. In addition, we investigated whether different species respond differently depending on their ability to adapt to the unfavourable shade environment caused by the overlying crop canopy.

\section{Materials and methods}

\subsection{General Procedure}

The test was carried out in 2000 and 2001 on a farm located in Asciano (Pisa) (43 43' North, $10^{\circ} 26^{\prime}$ East; $2 \mathrm{~m}$ above sea level) on silty clay soil (clay $35 \%$, sand $45 \%$, sand $20 \% ; 1.7 \%$ organic matter, $\mathrm{pH}$ 7.9) heavily infested by Datura stramonium L., Solanum nigrum L. and $\mathrm{Abu}$ tilon theophrasti Medicus. Maize was sown (hybrid FAO 700) on April 27 in 2000 and April 24 in 2001 on three large experimental plots $(30 \mathrm{x}$ $100 \mathrm{~m}$, one for each of the tested weed species) according to a geometric pattern (inter-row spacing $75 \mathrm{~cm}$, distance between plants along the row $20 \mathrm{~cm}$ ) so as to obtain a density of 6.6 plants $\mathrm{m}^{-2}$. Rows were north-south oriented and the crop was grown following the normal cropping practices used in the area. Three sub-plots (for each of the three tested emergence time, see below) were obtained $(10 \times 10 \mathrm{~m})$ in each plot. The geographic arrangement of the subplots was derived from the emergence dynamics of the present seedbank. Metereological data of experimental time are reported in figure 1. During the trial year hoeing was not carried out, nor were chemical herbicides used, so as not to disturb the natural propagation dynamics of weeds present in the plot.

\subsection{Crop Measurement}

Every $10 \mathrm{~d}$, height was measured on a sample of 10 plants selected at random in the plot. Data concerning leaves were collected every month. Such measurements were made monthly using a Leaf Area Meter (Li-Cor 3000, Li-
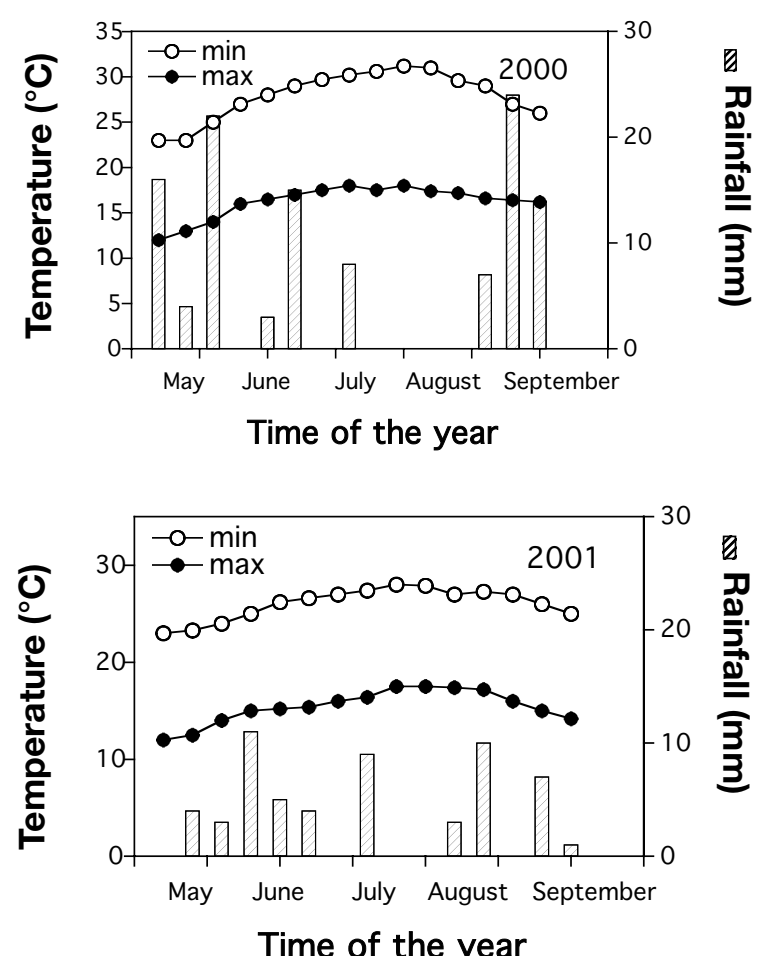

Figure 1. Metereological data over $10-\mathrm{d}$ periods referring to 2000 and 2001. 

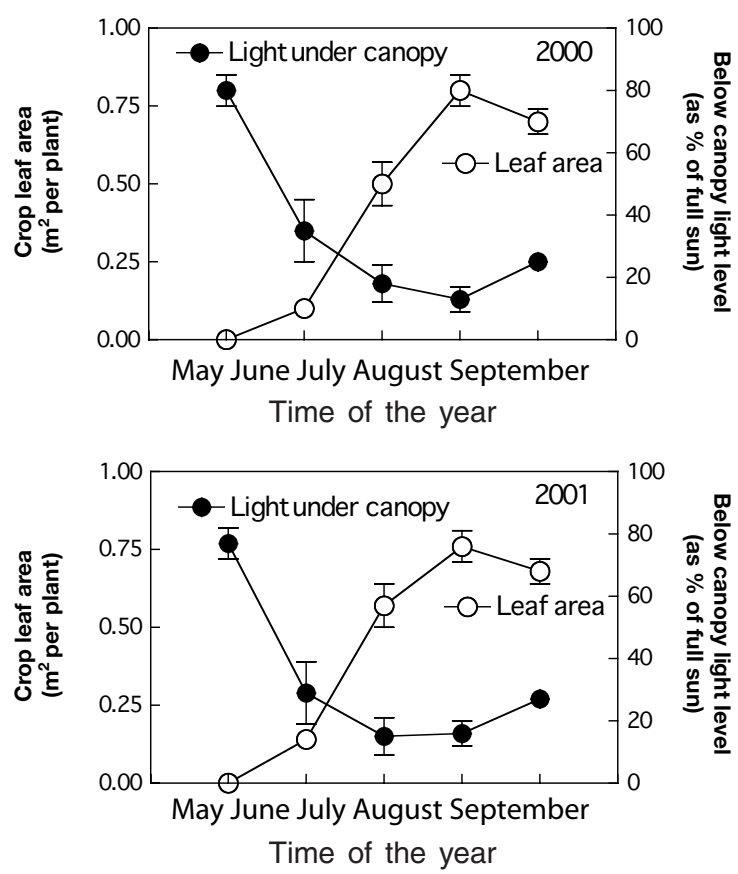

Figure 2. Height dynamics of both crop and weeds (Datura stramonium L., Solanum nigrum L. and Abutilon theophrasti Medicus during the experimental periods. The three weed species were grouped into three different emergence times (early, medium, and late). Vertical bars indicate the standard errors of the means.

Cor, Lincoln, NE 68504). Light levels reaching the soil surface (along the rows) below the crop canopy were also measured on the same dates. Light measurements were taken during the hours of maximum sunlight, using a pyranometer (Li-185B, Li-Cor, Lincoln, NE 68504).

\subsection{Weed Measurement}

Emerged weeds were identified and labeled with their respective date of emergence in order to group them into three periods: early (emergence peak around early May), medium (emergence peak around the end of June), late (emergence peak around early August). Only the three most abundant species were taken into account: Datura stramonium L., Solanum nigrum L. and Abutilon theophrasti Medicus, to ensure a sufficient number of emerged seedlings for each of the periods mentioned above. After labeling, the chosen weeds were isolated from other weeds (manual thinning): this was designed to promote competition between crop and weeds only, avoiding undesired and uncontrollable weed-weed interference. As with the crops, growth in height of each of the three weed species was determined.

Reproductive measurements (number of fruits per plant, number of seeds per fruit) were recorded at the normal time of crop harvest (12 October 2000 and 5 October 2001) on samples of 10 plants for each of the species examined (and for each of the 3 emergence periods). The sampling period was chosen in such a way as to assess actual annual seed production, since the above-mentioned agronomic disturbance coincides with completion of the seed production cycle irrespective of the degree of senescence of the various weeds. Tetrazolium tests (TTC) were also performed (ISTA, 1999) to evaluate viability of the seeds produced. Tests were additionally carried out on a sub-sample of 50 seeds for each of the plants examined. Total dry biomass was measured for the same plants (after 10 days in an oven at $60^{\circ} \mathrm{C}$ ) to calculate the harvest index values.

\subsection{Statistical Analysis}

The experimental design was a randomized block for plant development and the corresponding reproduction study. Seed viability evaluation was based on a completely randomized design. All data were subjected to ANOVA using Fisher's Protected LSD test (0.05 level of probability) for means separations.

\section{Results and discussion}

Figure 3 illustrates the growth in height of both crops and weeds during the trial period. Both $D$. stramonium and A. theophrasti, in which crop and weed emergence occur almost simultaneously, grew as tall as, or even taller, than the crop canopy. This finding was in agreement with the well known observation that "plant-plant competition" accompanied by lack of light causes further growth of the plants, which is indispensable in order to enable one of the plants to tower over the neighbouring vegetation and expose part of the leaves to an unshaded light environment (Smith, 1982). However, in spite of its early emergence, $S$. nigrum did not succeed in surpassing the height of the crop, although it maintained its photosynthesis system in the shaded environment. Shading reached values (Fig. 2) of $90 \%$ (compared to conditions of full sunlight) in the periods of full vegetative de- 

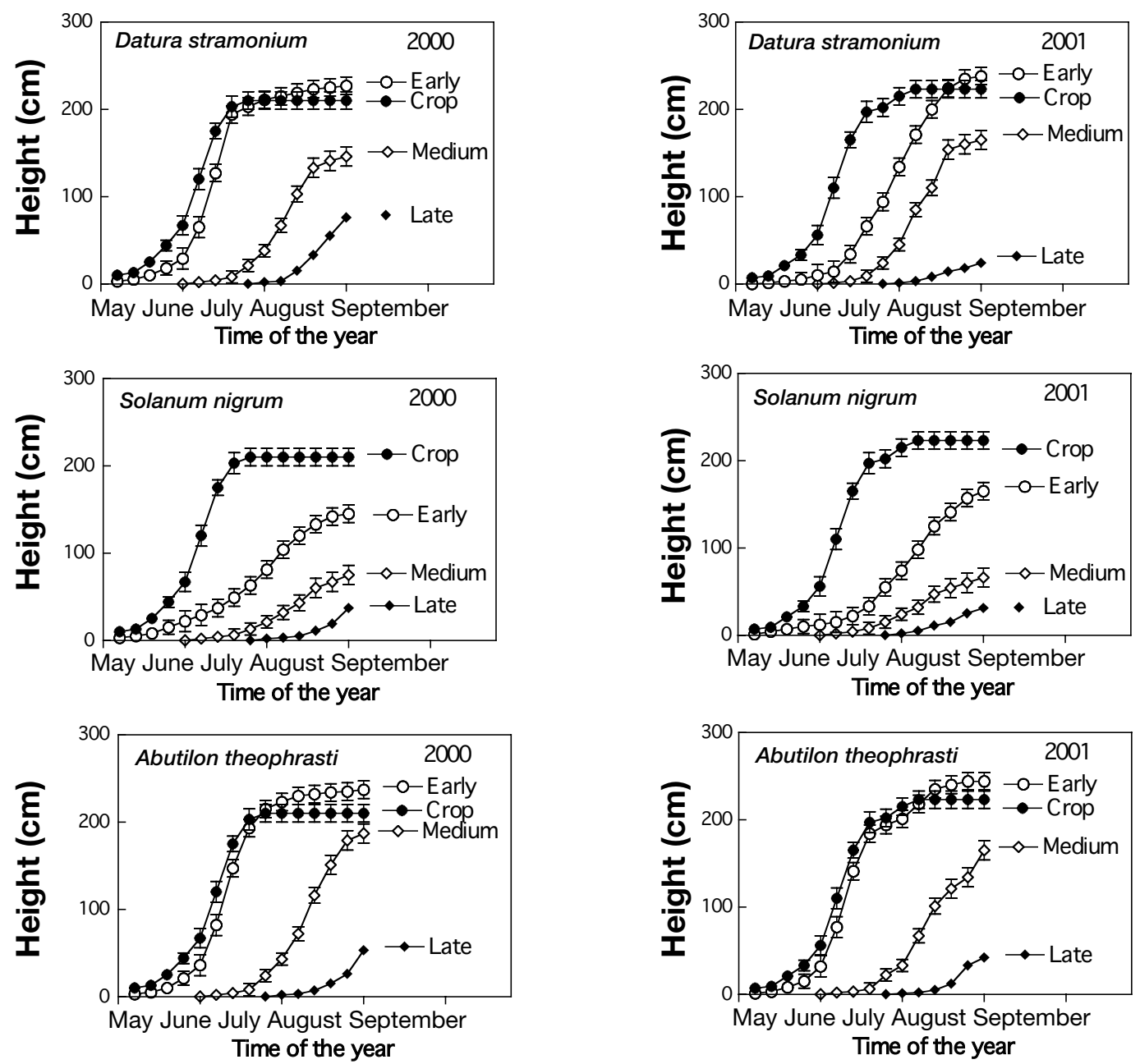

Figure 3. Crop leaf surface area and the relative shade production during the experimental period (spring-summer 2000 and 2001). Vertical bars indicate the standard errors of the means.

velopment (August) when the highest leaf area values were measured $\left(0.8 \mathrm{~m}^{2}\right.$ per plant $)$. It has already been pointed out that $S$. nigrum tends to react to lack of light by adjusting its photosynthesis system to shade conditions (McGiffen and Masiunas, 1992a) rather than by using up its energy reserves to grow in height. But even the other two species, D. stramonium and $A$. theophrasti, were unable to grow higher than the crop in cases when they emerged later than the crop (Fig. 3).

In spite of the various competition strategies adopted by the weeds under investigation, fruit production per plant was found to be strictly dependent on time of emergence (Figure 4). Thus delayed emergence consistently resulted in a significant decrease $(\mathrm{P}<0.05)$ in the number of fruits in all species studied. The decrease was, however, species-dependent: late emergence led to a $16 \%, 25 \%$ and $15 \%$ fruit reduction as compared to early emergence, D. stramonium., S. nigrum and A. theophrasti respectively. Moreover, the number of seeds per fruit was found to be constant (Fig. 4) in A. theophrasti (around 40 seeds per capsule) but variable in S. nigrum and even more in D. stramonium.

This considerable reduction in reproductive activity has been reported previously (Benvenuti et al., 1994) but was attributed almost exclusively to the decrease in fruits per plant, since no statistically significant variation in number of seeds per fruit was recorded. In the present case, 

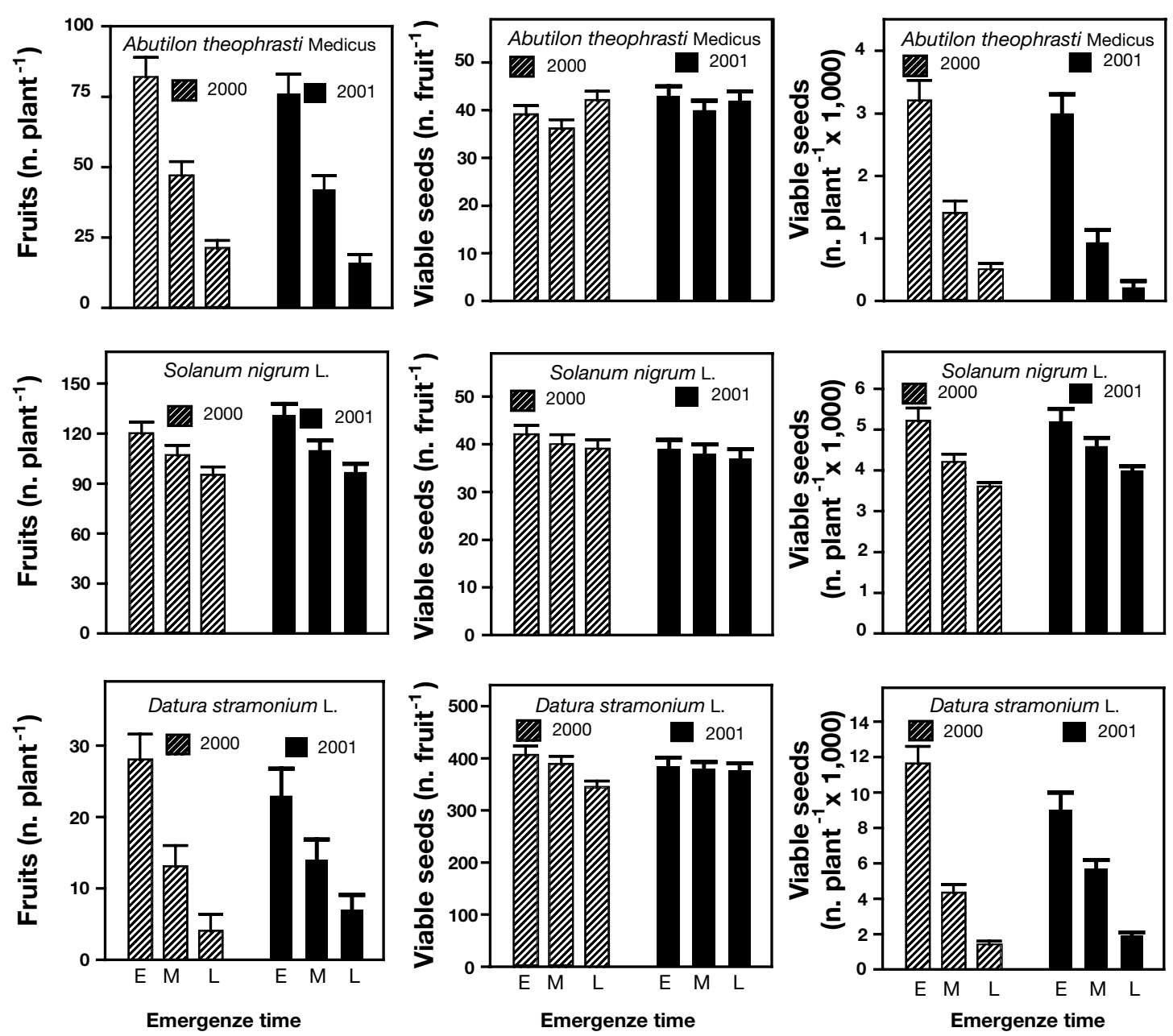

Figure 4. Number of viable seeds produced per fruit, number of fruit per plant, and total produced seeds per plant in the three tested weed species (Datura stramonium L., Solanum nigrum L. and Abutilon theophrasti Medicus) during the experimental period (2000-2001). Each emergence period was grouped in three different period: early, medium, and late emergence. Vertical bars indicate the standard errors of the means.

the twofold cause (decrease both in number of fruits per plant and number of seeds per fruit) of the drop in reproduction potential, with the exception of $A$. theophrasti, appears to be due to full competition both above ground and in the root system, whereas in the cited paper the artificial shade technique using plastic nets entailed only lack of light. Furthermore the chosen time of harvest in the present study (12 October 2000 and 5 October 2001) prevented full maturing and consequently full viability of a part of the seeds contained in the fruits. This result is in agreement with previous findings (Benvenuti et al., 1994) demonstrating that shading tends to delay the reproductive phase, thereby lengthening the biological cycle of the various species.
As a consequence of the drop in number of fruits per plant and seeds per fruit (with the exception of $A$. theophrasti), seed production per plant was dramatically reduced with late emergence (Fig. 5).

When weeds and crops emerged almost simultaneously, $D$. stramonium produced roughly 11,000 and 9,000 seeds per plant (in 2000 and 2001 respectively) and $S$. nigrum about 5,000 (in both years), while $A$. theoprasti produced over 3,000 (in both years). However, while for $D$. stramonium and late emergence entailed the production of only $15 \%$ of seeds, S. nigrum maintained $25 \%$ of the quantity of seeds produced in more favourable growth conditions. This behaviour is probably linked to the growth 
Figure 5. Harvest index percentage reached in both experimental periods $(2000$ 2001) by the three different weed species (Datura stramonium L., Solanum nigrum L. and Abutilon theophrasti Medicus) for early, medium, and late emergence. Vertical bars indicate the standard errors of the means.
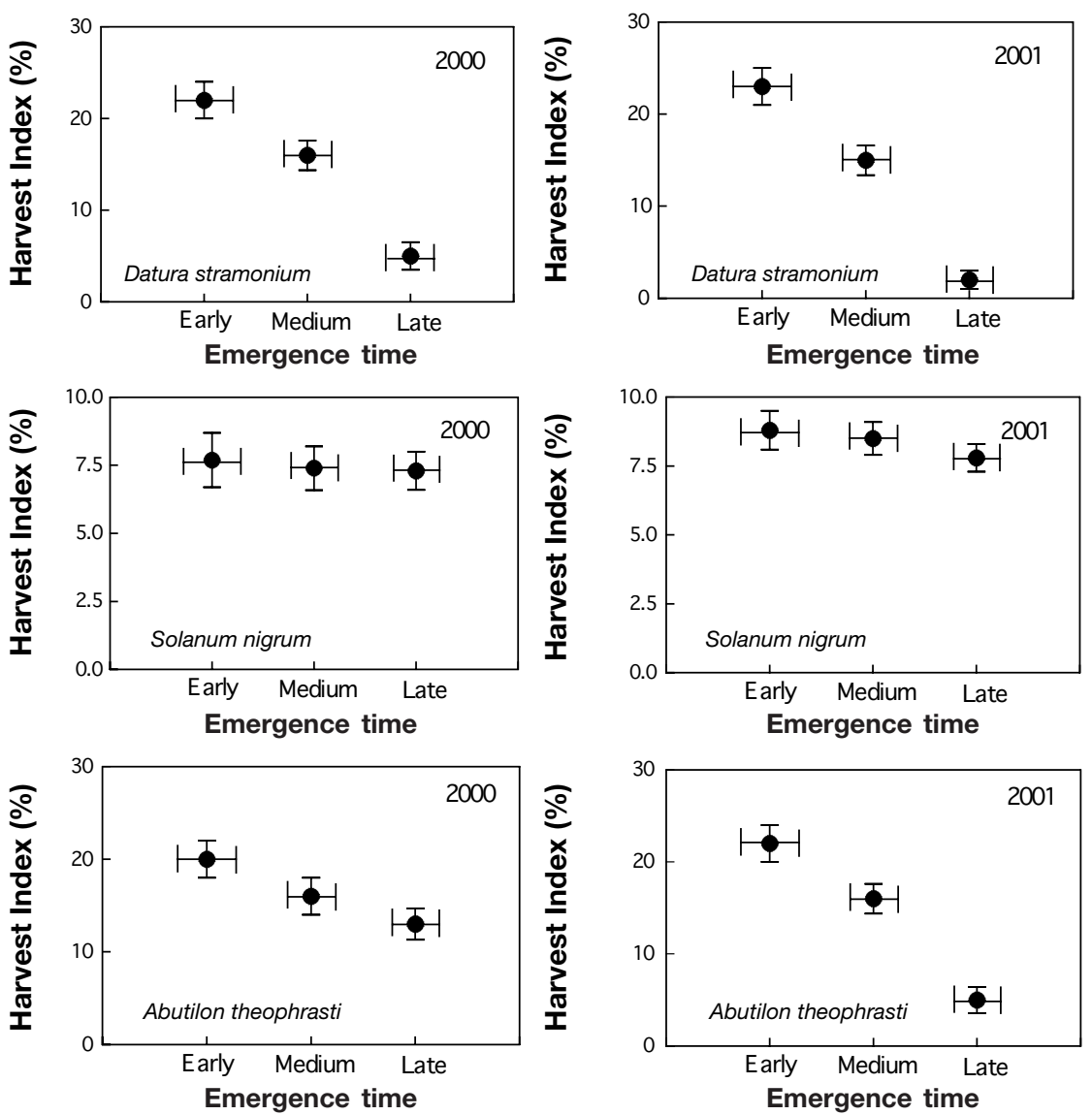

strategy characterizing the latter species, which is capable of competing and reproducing even in the presence of poor light thanks to its photomorphogenic (leaf expansion, McGiffen et al., 1992b) and photosynthetic (increase in chlorophyll concentration, Sattin et al 1989) adaptation. These two factors, together with reduced dark respiration, enable $S$. nigrum to adapt successfully to the lack of light (Boardman, 1977).

In the cases of early emergence, the strategy of stem elongation adopted by $D$. stramonium and $A$. theophrasti achieves success by enabling the plant to expose its photosynthesizing apparatus above the crop canopy. The stimulus to grow in height is mediated by phytochrome as a result of changes in the quality of incident light which is reflected horizontally (Sattin et al., 1994). This mechanism may be of strategic importance in providing an early signal of incumbent competition by neighbouring vegetation (Ballaré et al., 1990). Thus it is worth noting that crop height has been shown to play a crucial role in crop-weed competition (both in terms of growth and in relative seed production) not only in summer crops (Pendleton and Seif, 1962; Zanin and Sattin, 1988) but also in autumn-winter crops (Benvenuti and Macchia, 2000).

The harvest index values (Figure 6) confirm the two different strategies adopted by these weeds in competing for light. The need to exceed the crop in height determined a considerable decrease (significant for $\mathrm{P}<0.05$ ) in $D$. stramonium and $A$. theoprasti harvest index, when these species were at a competitive disadvantage because of late emergence. In these two species, values fell from $22 \%$ and $20 \%$ in conditions of early emergence to $6 \%$ and $13 \%$ in late emergence, respectively. In contrast, S. nigrum, which showed better adaptation to shaded environments, maintained similar harvest index values irrespective of growth conditions. Thus overall D. stramonium and $A$. theophrasti seem to have a competitive-ruderal growth strategy (Grime, 1979), while S. nigrum, although also a ruderal species (given its rapid 
and elevated seed production), appears to have greater stress tolerance and to adapt better to growing in shaded conditions. Consequently, $D$. stramonium and $A$. theophrasti can be controlled by agronomic measures focused on the increasing of the competitive ability for light (localization of the inputs, early sowing, rapid growth cultivars, etc.), while S. nigrum appears to persist successfully even in highly disturbed agricultural agroecosystems by virtue of its above-mentioned adaptive characteristics.

In other words, the time of weed emergence is of crucial importance in determining seed production, but its influence varies as a function of the strategies developed by weeds to adapt to adverse environmental conditions (ei. shade tolerance developed by S. nigrum). Such strategy of "shade tolerance" permit to reaching a good seed production in spite to the limiting light environment and thus to preserve the size of the "seedbank" at sufficient levels to ensure survival in a disturbed agroecosystem. In conclusion, the delay of weed emergence for physiologic (i.e. dormancy loss) or agronomic reasons [i.e. row hoeing due to the change of the "depth mediated" inhibition (Benvenuti, 2003)] is linked to a remarkable drop of seed production as a function of the strong interference with the crop in the phenological stage of full growth. Consequently these seedbank annual inputs do not appear to represent a relevant agronomic problem for the subsequent crops. On the contrary, the "sub-threshold" weed infestations (weed not controlled for the lack of economic convenience (Sartorato et al., 1996)) seem to assume a crucial role for the weed dynamics in the subsequent crops and further experiments are necessary in order to improve the optimization of rational strategies for the weed control.

\section{References}

Ballaré C., Scopel A., Sànchez R.A. 1990. Far-red radiation reflected from adjacent leaves: an early signal of competition in plant canopies. Science, 247:329332.

Baker H.G. 1974. The evolution of weeds. Ann. Rev. Ecol. System., 5:1-14.

Benvenuti S., Macchia M., Stefani A. 1994. Effect of shade on reproduction and some morphological characteristics of Abutilon theophrasti Medicus, Datura stramonium L. and Sorghum halepense L. Pers. Weed Res., 34:283-288.

Benvenuti S., Macchia M. 1997. Light environment, phytochrome and germination of Datura stramonium L. seeds. Envir. Exper. Bot., 38: 61-71.

Benvenuti S., Macchia M. 2000. Role of durum wheat (Triticum durum Desf.) canopy height on Sinapis arvensis $\mathrm{L}$. growth and seed production. $\mathrm{XI}^{\text {th }}$ International Conference on Weed Biology, 6-8 September 2000 Dijon France. pp. 305-312.

Benvenuti S. 2003. Soil texture involvement in germination and emergence of buried weed seeds. Agron. J., 95:191-198.

Brainard D.C., Bellinder R.R., Di Tommaso A. 2005. Effects of canopy shade on the morphology, phenology, and seed characteristics of Powell amaranth ( $\mathrm{Ama}$ ranthus powellii). Weed Sci., 53:175-186.

Boardman N.K. 1977. Comparative photosynthesis of sun and shade plants. Ann. Rev. Plant Phys., 28:355377.

Buhler D.D. 1999. Weed population responses to weed practices. I. Seedbank, weed populations, and crop yields. Weed Sci., 47:416-422.

Burnside O.C., Wilson R.G., Weisberg S., Hubbard K.G. 1996. Seed longevity of 41 species buried 17 years in Eastern and Western Nebraska. Weed Sci., 20:288300.

Canner S.R., Wiles L.J., McMaster G.S. 2002. Weed reproduction model parameters may be estimated from crop yield loss data. Weed Sci., 50:763-772.

Cardina J., Norquay H.M. 1997. Seed production and seedbank dynamics in subthreshold velvetleaf ( $\mathrm{Abu}$ tilon theophrasti) populations. Weed Sci., 45:85-90.

Grime J.P. 1979. Primary strategies in plants. Transactions. Botanical Society (Edimburg), 43:151-160.

ISTA. 1999. International rules for seed testing. Seed Sci. Technol., 27:50-52.

Mapes D.C., Rothwell G.W., Harwort M.T. 1989. Evolution of seed dormancy. Nature, 337:645-646.

Mauchline A.L. Watson S.J., Brown V.K., Froud-Williams R.J. 2005. Post-dispersal seed predation of non-target weeds in arable crops. Weed Res., 45:157-163.

McGiffen M.E., Masiunas J.B. 1992a. Prediction of black and eastern nightshade (Solanum nigrum and S.ptycantum) growth using degree-days. Weed Sci., 40:8689.

McGiffen M.E., Masiunas J.B., Hersketh J.D. 1992 b. Competition for light between tomatos and nightshades (Solanum nigrum or S.ptycanthum). Weed Sci., 40:220-226.

Mortensen D.A., Bastiaans L., Sattin M. 2000. The role of ecology in the development of weed management systems: an outlook. Weed Res., 40:49-62.

Moss S.R. 1983. The production and shedding of Alopecurus myosuroides Huds seeds in winter cereal crops. Weed Res., 23:45-51. 
Pendleton J.W., Seif R.D. 1962. Role of height in corn competition. Crop Sci., 2:154-156.

Perron F., Légère A. 2000. Effects of crop management practices on Echinochloa crus-galli and Chenopodium album seed production in a maize/soybean rotation. Weed Res., 40:535-540.

Sartorato I., Berti A., Zanin G. 1996. Estimation of economic thresholds for weed control in soybean (Glycine $\max$ L. Merr.). Crop Prot., 15:63-68.

Sattin M., Sartorato I., Merlo D. 1989. Influenza di due livelli di intensità luminosa su alcune caratteristiche fisiologiche e morfologiche di Solanum nigrum L. ed Amaranthus cruentus L. Rivista di Agron., 25:519526.

Sattin M., Zanin G., Berti A. 1992. Case history for weed competition/population ecology: Velvet leaf ( $A b u$ tilon theophrasti) in corn (Zea mays). Weed Technol., 6:213-219.

Sattin M., Zuin M.C., Sartorato I. 1994. Light quality beneath field-grown maize, soybean and wheat canopies - red: far red variations. Physiol. Plant., 91:322-328

Smith H. 1982. Light quality, photoreception, and plant strategy. Annu. Rev. Plant Physiol., 33:481-518.

Thompson K., Grime J.P. 1979. Seasonal variation in the seedbanks of herbaceous species in ten constrasting habitats. J. Ecol., 67:893-897.

Zanin G., Sattin M. 1988. Threshold level and seed production of Velvetleaf (Abutilon theophrasti Medicus) in maize. Weed Res., 28:347-352. 